\title{
An Approach to Qualitative Feature: Identifying the Beliefs of Knowledge Sharing in Practicing Communities
}

\author{
Mariela Isabel Oviedo Santillán \\ Universidad Andina Simón Bolívar \\ Marcelo Fernando López Parra \\ Universidad Andina Simón Bolívar
}

This documentary and exploratory work emphasizes a qualitative approach as a preliminary and complementary phase of the quantitative. The study is presented in the application of a case and the use of the Theory of Planned Behavior to identify behavioral, normative and control beliefs that influence the motivation in individuals to share their knowledge in communities of public organizations. For this, data was collected from applied interviews to experts of the Tax Administration in Quito-Ecuador. The data were classified and codified in words, expecting the recognition of 63 beliefs which will allow the construction of a questionnaire in the future that validates the relationships between the variables of the motivation model used. In the documentary review, the strengths of qualitative and quantitative are contrasted, their incompatibility is rejected and the selection of hybrid approaches is encouraged, highlighting the best of each method and exemplifying the use of qualitative methods in the construction of typologies of case narratives and modal narratives as categories in the quantitative analysis.

Keywords: qualitative research, mixed methods, communities of practice, knowledge sharing, motivation, public administration

\section{INTRODUCTION}

The discussions of a simplistic division of qualitative versus quantitative methods have now been replaced by a focus on the implications of different logics for research and knowledge development (Haverland and Yanow 2012). This is reflected in the exponential growth of quantitative research, accompanied by the parallel and continuing development of its counterpart (Cassell and Symon 2015).

In this context, qualitative can be seen as a well-established methodology capable of answering major research questions and useful for strengthening theoretical-practical links, which is consistent with the explosion of reflections on quantitative studies and methodology in the social and administrative sciences in recent years.

Qualitative methodology has a long history and tradition within organizational and management research. Contributing to the understanding of managerial experience and practice, the first ethnographies on managerial work date from the 1950s, 1970s and 1980s, with works such as Dalton's Men Who Manage (1959); Watson's The Personnel Managers (1977); and Jackall's Moral Mazes: The World of Corporate 
Managers (1988). Later, it was argued that qualitative techniques can - in general - provide powerful tools in management and organizational research Cassell and Symon 2006).

Qualitative work covering the various fields of organization, management and marketing can now be found in all areas of management (Cassell and Symon 2006).

Despite this emergence in the empirical field, the predominance of quantitative research is undeniable (Ospina, Esteve and Lee 2017). Then, it is mandatory to ensure that both types of methodology have the same position regarding the legitimacy of knowledge claims generated by empirical research (Ospina, Esteve and Lee 2017). Exemplifying their use as we aim to do here and improving the quality of qualitative research reports can help this goal (Ashworth, McDermott, and Currie 2018).

Now, criticisms of qualitative research no longer revolve around the advantages and disadvantages with respect to its quantitative peer, but rather that the reports are opaque (Ospina, Esteve and Lee 2017) and that there is a need for explicit, consistent and transparent choices throughout the research process (Dodge, Ospina and Foldy 2005).

This makes the transparency claims to be related to better designed research, the transition from data collection to analysis, and how the information underpins the contribution. However, agreement on standard evaluation criteria prove challenging because of the plurality of qualitative approaches (Ospina, Esteve, and Lee 2017).

Although quantitative studies also show methodological diversity, the underlying and evident philosophical differences of qualitative methods makes it difficult to apply a generic template to assess their scientific rigor especially when it is not easy to apply standard tests of validity and fit to qualitative approaches (Dodge, Ospina, and Foldy 2005). Thus, there is concern that judgments of qualitative research are often based on a problematic definition of quality and the wrong criteria; consequently, scholars accept a version of rigor in a way that reduces the plurality of qualitative research, or rejects the concept to undermine its legitimacy. This suggests that there is a need to strike a better balance between rigor and richness, and to develop broader principles so that qualitative research underpins theorizing and accommodates plurality (Dodge, Ospina, and Foldy 2005)

On the other hand, the success of the method used - qualitative or quantitative - will depend on the nature of the academic work. There is no point in asking whether one methodology is better than the other: there will be research that makes use of only one method, but at other times both options will be required, i.e., empirical and quantitative research techniques will be selected and used. There is no need to opt for one of the two approaches, but rather to determine how the strengths of each approach can be combined, which will enrich and deepen the results of the research proposals.

Supporting the combination and seeking to contribute to the growth and dissemination of this approach, this paper aims to present the main concepts of quantitative, qualitative and mixed methodologies, emphasizing the first one and exemplifying the determination of the beliefs of individuals as a basis for the construction of a standard questionnaire that in the future -through the quantitative- will be used in the study of the relationships between motivation and knowledge sharing in communities of practice of public organizations.

This paper is structured in four sections. The first section introduces qualitative research and the second section presents the benefits and advantages of quantitative, qualitative and mixed research. It ends with some reflections, but not before exemplifying the use of qualitative research as a complement and previous phase of quantitative research.

\section{Qualitative Research: Some Assumptions}

The qualitative current has its origins in the social sciences, particularly in sociology, Chicago cultural anthropology, Berger and Luckmann's treatise (1967) and the sociology of knowledge. Taken together, these trends represented a movement against positivism, a reaction to the revolution in the methods employed in the social sciences in the 19th and 20th centuries (Brower, Abolafia and Carr 2000), which were deemed incapable of addressing the complexity of social phenomena (López Herrera and Salas Harms 2009). 
Qualitative research is known by a variety of names, including constructivist research (in Brower, Abolafia and Carr 2000). These varieties of terms have generated diverse classification schemes that, in addition, identify many qualitative research approaches. Thus, for example, a single publisher, Sage, offers approximately 140 options on qualitative methods, which, depending on one's point of view, could represent a blessing or a problem.

To summarize, the qualitative studies range from ethnography of individual cases, through comparisons, to large sets of information based on techniques such as data collection, interviews, direct and participant observations, and document collection and review. This produces multiple forms of qualitative data including direct quotations, verbatim notes, and documentary excerpts (Ashworth, McDermott, and Currie 2018).

The present article focuses on the content analysis of the interview, considered primarily as a technique of document interpretation-text, image, sound or any other record that is "based on reading as an instrument for gathering information, which unlike common reading [...] must be systematic, objective, replicable and valid" (Abela 2016, 2).

Thus, the texts to be analyzed must be understood both in their explicit and latent forms; that is, there are hidden texts made up of signals and insinuations that the interviewee may manifest while expressing his or her answers. In addition to all this, the analysis has a certain additional complexity, since the study of the data begins with their generation: the relationship between the interviewer and the interviewee must be managed, especially with respect to the possible biases of the interviewer and the interviewee.

Therefore, it is reiterated that the application of this type of analysis requires that the answers be understood in their literal sense and beyond, and that it is important to consider the situation of the author of the text and his or her circumstances. Therefore, a fundamental methodological part is to obtain the voice of several collaborators, so that consensus and controversies can be established that in turn show high points or edges to be considered in the analysis under study.

Under this scheme, even an incomplete response or lack of response can be an important source of analysis, even more so when it occurs constantly during data collection.

At a general level, content analysis seeks to structure the information presented in a free form; that is, the main purpose of this deep reading is to generate elements of meaning that allow verifying where the texts converge and where they diverge. In most cases, this structuring is established by means of grounded theory, the fundamental premise of which is that the findings emerge from the data. Consequently, the aim is to identify units of analysis - common ideas related to the object of study that take the form of a pattern - and then to carry out coding and categorization, which is the final product of this type of analysis.

The coding is contrasted with the theory linked to the object of study. These force-ideas are fully defined, including their relationship with other similar ones in the categorization. These categories "make it possible to assign common meanings to the information compiled during an investigation" (Narvaez 2014, 11).

Currently, there are several specific computer applications that facilitate the coding and categorization of content analysis, not only by creating word frequency matrices, but also by identifying synonyms, lexical families and even schemes that show how predicates are tied to the subjects defined by the researcher. With the use of these applications, the possibility of managing a large number of texts of different natures has exponentially increased, but the selection criteria and how the propositions respond to the study objectives should not be left aside.

In this study, the QSR International software, called NVivo version 10, was used, which allows the optimization, analysis and search for perspectives in qualitative or unstructured data, such as interviews, answers to open-ended questions (surveys) and web content and social networks. Before developing an example, it is worth making some clarifications regarding qualitative and quantitative research paradigms, because the proposed practical application fits within the framework of mixed proposals, with emphasis on qualitative research. 


\section{THE QUALITATIVE, THE QUALITATIVE AND THE MIXED}

It would seem that in the social sciences there is a sharp division between qualitative and quantitative research (Ragin, Nagel and White 2004). Quantitative research assumes that reality can be objectively represented as an abstraction of real life, and qualitative research assumes the presence of multiple realities, constructed by various participants as they engage in their own daily local experiences (Brower, Abolafia, and Carr 2000).

Another difference is that qualitative research studies structural-situational environments and quantitative research studies the association between quantified constructs. Avoiding quantification, qualitative research differs from its peer in that it is based on narrative descriptions and makes use of techniques such as, for example, observation and unstructured interviews, in order - as far as possible - to identify "the deep nature of realities, their system of relationships, their dynamic structure" (López Herrera and Salas Harms 2009, 131). On the other hand, and seeking the generalization of results, the quantitative determines the strength of the correlation of variables through the study of a sample and inference on a population (López Herrera and Salas Harms 2009).

In addition, with respect to the way in which they capture knowledge, while quantitative researchers try to remain separate from the participants to prevent them from reacting to their presence, qualitative researchers believe that subjectivity is inevitable in the social sciences and consider that the phenomena worth studying are those that are considered significant precisely because the spectators attach value to them.

In another sense, quantitative researchers introduce subjectivity even in their choices of topics and sites of study, and in the ways in which they define variables. They pursue and insist that they generate unbiased and value-free data; qualitative researchers, on the other hand, highlight their value orientations and those of their participants, although, in pursuing credible conclusions, they try to keep them in oblivion.

Quantitative reports are often written in the third person, past tense, presumably to enhance the researcher's sense of detachment and value-free representation; qualitative researchers, in contrast, often use the present tense and first person plural pronoun (we) to help couch reader participation in the interpretation of the evidence being presented and illuminate the researcher's presence in the study (Brower, Abolafia, and Carr 2000).

Despite the differences and from the point of view of this study, the view of Ragin, Nagel and White is assumed, who, rather than a duality, state that qualitative and quantitative research lie on "a continuum in which two clearly defined extremes can be identified" $(2004,9)$. At one end is the former, which rejects the concepts of traditional theory on the grounds that it is dubious, and that in the research process the distinction between the object studied and the examiner is blurred. At the opposite extreme, quantitative research is characterized by considering objectivity in the analysis of clearly identified populations, cases and variables, assuming that the relevant theories and hypotheses are well specified. But, in addition, and in between the two extremes, there are hybrid and combined research strategies that contemplate both qualitative and quantitative methods.

Researchers often use these mixed methods. For example, qualitative strategies may be used to obtain information on meaning, affect and culture, while quantitative strategies are used to measure structural, contextual and institutional characteristics. In the words of Tashakkori and Creswell (2007), in mixed methods the researcher collects and analyzes information, integrates the results and makes inferences through quantitative and qualitative methods in the same study. It involves combining quantitative and qualitative data collection and analysis in the same research.

Other combinations of qualitative and quantitative approaches include hybrid strategies. This is the case selected in this proposal, as qualitative methods are used to construct typologies of case narratives from indepth interview data, and then, in the future, modal narratives are used as categories in the quantitative analysis.

In general, qualitative and quantitative research are complementary approaches. The former can provide what is often missing in the latter, such as evidence about mechanisms and meanings. Many hypotheses 
can be quickly eliminated on the basis of qualitative research, just as various ways of finding specific types of evidence can be obtained.

With the combination of methods, the qualitative phase can be understood as a relatively inexpensive prologue to a forthcoming large sample investigation, i.e., an informal pretest that refines hypotheses and measures (Ragin, Nagel, and White 2004).

Other common combinations contemplate the use of qualitative methods in the final stages of largesample research because causal mechanisms are rarely visible in conventional quantitative research; they usually must be inferred. Thus, qualitative methods can be useful in assessing the credibility of these mechanisms. Typically, these designs involve an in-depth study of a carefully selected small sub-sample of cases from the large sample study.

The cases chosen can be examined in varying degrees of detail, depending on the researcher's objectives. The qualitative methods used at this stage range from the in-depth interview (the most common qualitative adjunct) to detailed observation of the situation and environment of each case.

A third use is when it is possible to integrate qualitative data collection techniques into a large sample study. Several researchers have used storytelling devices, sometimes in a quasi-experimental design, to elicit meanings from respondents and related subjective phenomena. While these studies are still predominantly quantitative in nature, there is at least an attempt to address some of the limitations of conventional quantitative methods.

Finally, some researchers attempt quantitative and qualitative analysis of the same cases. This strategy is common when samples are of moderate size (e.g., an $\mathrm{N}$ of 30); they are employed when researchers seek to demonstrate that the results of quantitative and qualitative analyses are complementary. With a moderate number of cases, it is possible to establish a reasonable degree of familiarity with each, so as to confront them all as distinct cases. At the same time, the $\mathrm{N}$ of cases is sufficient for simple quantitative analyses (Ragin, Nagel and White 2004).

In summary, there are many strengths and weaknesses of quantitative and qualitative in social research. There are extreme positions, but there is also a moderating view that advocates complementarity, i.e., that both types of research are valid, mutually supportive and mutually recognized (McNabb in White-Peck 2006): given the nature of the study, qualitative and quantitative research techniques are selected and used, resulting in a mixed view, which allows the hypotheses to be strengthened and the research results to be deepened (McNabb in White-Peck 2006).

\section{AN EXAMPLE OF QUALITATIVE AS A PHASE PRIOR TO QUANTITATIVE}

The following section shows, by means of an example, how qualitative methods-as a preliminary test to refine hypotheses and measures-can be used to solve a specific research problem. To this end, the background and theory employed, the research design, the interviews collected and the method of data analysis are explained, with the aim of exposing the use of empirical research in the field of management.

\section{BACKGROUND AND THEORY}

Using the theory of planned behavior (TPB), the aim is to identify possible background factors that may influence the knowledge sharing behavior of communities of practice in public organizations.

TPB holds that human behavior is voluntary and that individuals make rational choices to engage (or not) in a given behavior. The choices made are influenced by individuals' own beliefs about the outcome and assessment of the advantage (or disadvantage) of engaging in the target behavior. These assumptions underlie three conceptually distinct beliefs: behavioral, normative, and control beliefs. The former refers to perceived beliefs about the likely outcomes of engaging in the target behavior and the evaluation of the desirability of these outcomes; the latter have to do with perceived social pressure; and the latter deal with the perceived ease or difficulty of engaging in the desired or undesired behavior (Ajzen 1991) 
FIGURE 1

THEORY OF PLANNED BEHAVIOR

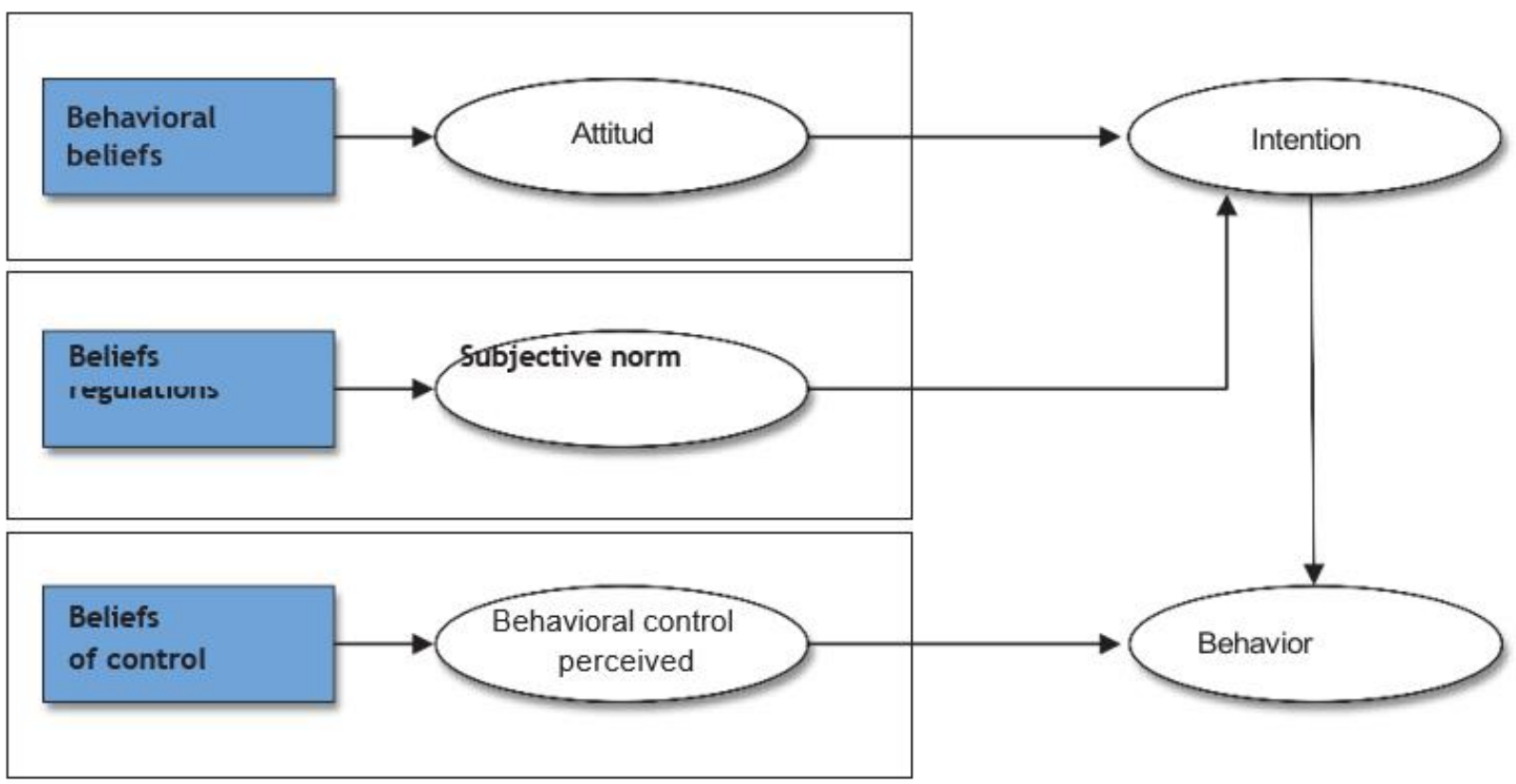

Source: adapted from Aizen (1991).

In their respective sets, behavioral beliefs generate an attitude towards behavior, normative beliefs result in the subjective norm, and control beliefs give rise to perceived behavioral control. Thus, attitudes reflect people's positive and negative evaluations in relation to adopting a behavior, while subjective norms - or social pressure to perform or not perform an act - show the social influence people feel in relation to possible behaviors, and perceived behavioral control is the expected ease or difficulty of performing a behavior, a reflection of individuals' past experiences, as well as an anticipation of impediments and obstacles (Aizen 1991).

The closest predictors of behavior are intentions, which in turn are preceded by attitudes, subjective norms, and perceived behavioral control. By virtue of this, the more favorable the attitude and subjective norm with respect to a behavior, and the greater the perceived behavioral control, the stronger should be the person's intention to perform the behavior under consideration. Intention is thus assumed to be the immediate antecedent of the behavior (Aizen 1991). Finally, to the extent that perceived behavioral control is veridical, it can serve as a proxy for accurate control and contribute to the prediction of the behavior in question.

In short, TPB considers that attitudes toward a given behavior, the existence of subjective norms, and an individual's perceived control are three fundamental antecedents for a person to define his or her behavioral intention. Intention - together with the direct effect of perceived behavioral control - is thus the antecedent to behavior.

To complement the theoretical underpinning, communities of practice (COP) are defined as groups of people, informally united by shared experience and joint enthusiasm for the enterprise, who interact on a continuous basis sharing their concerns, problems or passion for a specific topic, and who deepen their knowledge and experience in a given area of knowledge. With the creation and dissemination of new knowledge generated in COPs, a double benefit effect is obtained in the heart of public affairs: on the one hand, there is an increase in the organizational commitment of individuals and greater knowledge of institutional processes and strategies; on the other hand, the organization's practices acquire greater quality and become standardized (Martínez Marín 2008). Likewise, communities of practice favor connections 
between individuals in formative structures, although it is first necessary to overcome several organizational issues (Wenger 2001).

While identifying these issues, the public sector is recognizing the importance of less formal processes of sharing, socializing and creating knowledge among peers and within small groups with related interests, a recognition that seeks to contribute to the promotion of change and the diffusion of innovation in this type of organizations. In this context, the key questions that arise are: What are the beliefs that determine the knowledge sharing of communities of practice in public administration? What is the influence of these motivational beliefs on the processes of knowledge creation and sharing in communities of practice in public organizations?

The objective of this study is to offer an answer to the first question, through the use of qualitative methodology. In the future and with the quantitative, the second question will be solved, considering that the qualitative is a premise of the quantitative and, therefore, the usefulness of combined, hybrid or mixed methodologies is resorted to and evidenced.

\section{METHODOLOGY AND DESIGN OF THE RESEARCH}

This work uses the hybrid design, giving priority and emphasis to the qualitative part. In terms of Morse (1991), whose system uses the abbreviations qual and quan to represent qualitative and quantitative, respectively, this research is of the QUAL, quan type. Note the capital letters to emphasize the predominance of the qualitative.

On the other hand, the arrow symbol $(\rightarrow)$ is used because it is a QUAL $\rightarrow$ quan sequence design: first the qualitative and then the quantitative. The symbol (+) would be used to indicate a simultaneous design, which in this case does not apply. According to the above, this research is classified in the different importance and sequential QUAL $\rightarrow$ quan type.

According to Creswell and Plano Clark (in Molina Azorín et al. 2012), this study is categorized as exploratory because its purpose is, in the first place, to carry out a prior analysis in order to determine the motivational beliefs, that is, to identify the most appropriate measures and variables that, later and through the construction of an instrument for data collection (survey), will be used in the second part of the research. The preliminary analysis is developed through qualitative research, while the second part will be quantitative; that is, we are dealing with a two-phase sequential design.

In order to test the proposed research model, the in-depth interview method was adopted to collect the data and as a procedure to elicit behavioral, normative and control beliefs, according to the TPB. Subsequently, the information was examined by applying the coding method and considering that the unit of analysis is the individual.

It should be noted that the TPB is made up of hypothetical and predictor variables. The former, also called latent variables, are the theoretical constructs that make up the TPB, and cannot be directly observed, but inferred. The latter can be assessed directly, through the responses of individuals and the use of scales (Likert, Thurstone, among others), as response options to the questions posed by the evaluator.

Although interesting findings are achieved, direct measurements of the TPB constructs cannot be obtained by using arbitrary questions or questions chosen in the analysis of previous studies (approximation), because "measurements with relatively low reliability may be produced and may lead to an underestimation of the relationships between the constructs of the theory and its predictive validity" (Ajzen 2002, 3). In that sense, to ensure that measurements are reliable and consistent, and because there are an infinite number of variables for different behaviors and populations, it is vital to select appropriate items in the research.

Attitude, subjective norm and perceived behavioral control can be measured indirectly based on beliefs, but their identification requires prior work - using an interview - in which participants are provided with a description of the behavior of interest and asked to answer a series of questions related to the advantages and disadvantages, the individuals or groups whose behavior they would approve or disapprove of, and the factors or circumstances that would enable or disable them from carrying out the behavior of interest. 
The responses obtained are used to identify the accessible personal beliefs -that is, the unique beliefs of each research participant- or to construct a list of the accessible modal beliefs in other words, the most commonly held beliefs in the research population (the reason for the present study). These modal and accessible beliefs will provide the basis for constructing the standard questionnaire, which will later be used in the main study and which contains several items that will assess a given construct (Ajzen 2002).

It is necessary to emphasize that the scope of this paper contemplates the identification of TPB behavioral beliefs as an example of the use of qualitative strategies and as a preliminary work for the subsequent use of quantitative collection instruments and analysis techniques.

\section{IMPLEMENTATION AND ANALYSIS OF INTERVIEWS}

As already indicated, through the application of interviews and the analysis of the data with categorization, the beliefs that were over-salient for the target population (public servants) were identified, once they were confronted with a specific scenario of knowledge sharing in the communities of practice. confronted with a specific scenario of knowledge sharing in the communities of practice.

The selected sample is made up of thirteen civil servants who are experts in the field and belong to the Department of Quality Management and Institutional Change ${ }^{1}$ of the Internal Revenue Service (SRI), a public institution of Ecuador with national jurisdiction, whose mission is to manage the country's tax policy. In other words, it is responsible for the administration and collection of taxes at the national level.

In all cases, the interviews were conducted in the experts' offices, after planning the appointment by telephone, in which the purpose of the research was briefly explained. Their average duration was 45 minutes, which corresponds to the standard for interviews of this type (Coller 2000). The selected servers were asked to participate individually and answer seven questions; they were previously presented with a brief explanation of the study behavior and were given a few minutes to organize their thoughts. All interviews were recorded in written form.

With the help of the NVivo program, a word frequency search was carried out in order to make a first approach and get an idea of the content most frequently repeated in the interviews. Subsequently, the texts of each interview were read and explored to establish the conceptual framework of the study through the use of interactive nodes, i.e., categorizing based on behavioral beliefs. The answers to the two initial questions determined the behavioral beliefs, those to the third and fourth questions served to identify the normative beliefs, and those to the three final questions established the control beliefs.

The following are the questions and some of the respondents' responses that serve as examples.

For behavioral beliefs:

Interviewer: What, in your opinion, are the advantages of sharing knowledge in the IRS COPs?

Informant A: Having a unified network of criteria in which any server can access to consult the response issued to their concern, and above all maintain a single criterion towards citizens who demand attention. On the other hand, in the discrepancy of criteria, consensus can be reached, based on the regulations in force and the experience of officials with institutional trajectory. If necessary, procedures or instructions can even be drawn up to keep the employees on the same line of argument and to provide a response to the citizenry: to grow professionally, which helps the organization to grow and improve its internal and external image.

Interviewer: What, do you think, are the disadvantages of sharing knowledge in the IRS COPs?

Informant B: If the information is not truthful, it can generate reprocessing and crosschecking of the shared knowledge. 
The opinion of informant A showed that behavioral beliefs fit into the categories of COPs as a mechanism that ensures the unification of criteria and professional growth, while informant B categorized COPs as detrimental, considering them as spaces for the dissemination of unofficial erroneous information.

Most of the responses related to behavioral beliefs (40\%) affirmed that COPs improve the execution of processes in the organization, allow the unification of criteria and prevent the leakage of knowledge in the institutions. These findings do not coincide with the existing literature.

Authors such as Bock et al. (2005, 82) and Jeon, Kim, and Koh $(2011,267)$ propose that "good," "pleasant experience," "valuable to me," "a wise move," and "detrimental" are factors or behavioral beliefs that influence the likely outcomes of engaging or not engaging in COP knowledge com- partitioning.

Regarding social beliefs:

Interviewer: Which individuals or groups would approve of you sharing knowledge at COPs?

Informant C: I feel that I have the support of my direct line of supervision.

Interviewer: Which individuals or groups would disapprove of you not sharing knowledge at COPs?

Informant D: In my criterion, the authorities, high and middle management.

The responses of informants $\mathrm{C}$ and $\mathrm{D}$ were straightforward, as were most of the criteria of the respondents in the selected sample (73\%): immediate management, authorities and peers. These categories coincide with previous research proposals, which point out that CEOs, immediate management, team members and leaders are the factors that exert social pressure on individuals participating in a COP (Bock et al. 2005; Jeon, Kim and Koh 2011).

To conclude, the interviews of control beliefs:

Interviewer: What are the factors or circumstances that would make it easier for you to share knowledge in the IRS COPs?

Informant E: I think highly trained personnel: there are no experts, or there is a lack of ability on the part of the experts to transmit knowledge effectively. That the leaders of the organization see it as something strategic and give it momentum, because it is a competitive advantage for the organization.

Interviewer: What are the factors or circumstances that would make it difficult or impossible for you to share knowledge in COPs?

Informant F: Lack of budget availability to encourage sharing initiatives. Lack of synergy between people. Lack of trainers, facilitators, experts.

Interviewer: Are there other issues that come to mind when you think of the difficulty of sharing knowledge in the SRI COPs?

Informant G: Lack of time, there is no priority for initiatives of this type. Experts do not have time. There is no comprehensive incentive plan to encourage people to learn or participate in knowledge transfer processes.

When the responses of informants $\mathrm{E}, \mathrm{F}$ and $\mathrm{G}$ were analyzed, the criteria expressed in the first case could be classified into the categories of lack of expertise, lack of sharing skills and lack of teamwork. 
In the second opinion, the categories lack of financial resources and lack of expertise were evident; and the third opinion fell into the categories of excessive workload and lack of an organizational strategy for knowledge sharing.

These findings are in contrast to proposals such as those of Chau and $\mathrm{Hu}$ (2001) and Jeon, Kim, and Koh (2011), which identify com- partitioning skills, resource provision, and knowledge to handle computer support systems as factors that facilitate or hinder knowledge sharing behavior.

It would seem that the findings of this study do not match the existing literature, but, far from being a mistake, the TPB does not specify beliefs, it simply points to a large number of possible background factors that can influence individuals and depend on the types of behavior and cultures studied (Ajzen 2011). The factors identified in this qualitative phase are therefore expected to indirectly influence COPs' knowledge sharing intentions and behavior.

Thus, 25 accessible behavioral, 7 normative and 31 control beliefs were identified using NVivo 10 software; for this purpose, 63 categories were created to classify the opinions expressed by the selected sample. Table 1 shows the most important beliefs with the highest percentages.

TABLE 1

\section{BEHAVIORAL, NORMATIVE AND CONTROL BELIEFS OF SRI}

\begin{tabular}{|c|c|c|c|c|}
\hline No. & Name & References & Classification & Percentage \\
\hline 1 & $\begin{array}{l}\text { Improvement in the execution of processes } \\
\text { in the organization. }\end{array}$ & 12 & \multirow{3}{*}{ Behavioral beliefs } & $23 \%$ \\
\hline 2 & Unification of criteria. & 5 & & $9 \%$ \\
\hline 3 & $\begin{array}{l}\text { Avoids knowledge leakage in the } \\
\text { organization. }\end{array}$ & 4 & & $8 \%$ \\
\hline 4 & Immediate management. & 11 & \multirow{4}{*}{ Normative beliefs } & $42 \%$ \\
\hline 5 & Authorities. & 5 & & $19 \%$ \\
\hline 6 & Training area of the organization. & 3 & & $12 \%$ \\
\hline 7 & Colleagues. & 3 & & $12 \%$ \\
\hline 8 & $\begin{array}{l}\text { Lack of an organizational strategy for } \\
\text { knowledge sharing }\end{array}$ & 7 & \multirow{4}{*}{ Beliefs of control } & $13 \%$ \\
\hline 9 & $\begin{array}{l}\text { Excessive workload, which does not allow } \\
\text { participation in knowledge sharing } \\
\text { initiatives. knowledge sharing initiatives }\end{array}$ & 7 & & $13 \%$ \\
\hline 10 & Lack of experts. & 3 & & $6 \%$ \\
\hline 11 & $\begin{array}{l}\text { Lack of awareness of the benefits of } \\
\text { knowledge sharing }\end{array}$ & 3 & & $6 \%$ \\
\hline
\end{tabular}

Source and self-elaboration.

With the selected accessible personal beliefs, the standard questionnaire will be developed, which is the subject of another research paper and which, after data processing and with the use of quantitative methods, will make it possible to identify the causal relationships between attitudes, intention and sharing behavior in COPs.

\section{FINAL THOUGHTS}

The choice of the method used will depend on the nature of the study, the object and its objectives. It could be considered that, as opposed to quantitative, qualitative methods pay more attention to deepening 
rather than generalizing the results of the research. For example, qualitative methods can be used to obtain information about meaning, affect and culture, while quantitative methods are used to measure institutional, structural and contextual characteristics.

The selection of a mixed method has methodological advantages that enrich the research. There are many possible combinations and they have advantages, such as deepening and diversifying the information, providing methodological value for accepting or rejecting the theories employed, and providing procedural security for postulating the presence of causal relationships. But as in everything, there are also disadvantages; in this case, in the choice of methodological pluralism, the drawbacks are related to the costs of research, time and duration of the work.

With respect to the example used, this paper succinctly describes the process suggested by Ajzen and his theory of planned behavior for the identification of beliefs that will later be used in the construction of a questionnaire to evaluate the attitude, the subjective norm and the intention to share knowledge in the communities of practice of public organizations. With this qualitative work and making use of categorization, the behavioral beliefs of Ecuadorians working in the public sector have been identified, as opposed to the bad practices of researchers who assume that the direct measurements of the TPB constructs (beliefs) are adaptations of items used in previous studies.

Although this approach often achieves interesting findings, it can generate measurements with low reliability and lead to an underestimation of the relationships between the constructs of the theory and its validity. Therefore, constructs should be used for each behavior and for each predictive population (Ajzen 1991).

In addition, and given that in the TPB the most detailed substantive information on the determinants of a behavior is contained in a person's beliefs, this proposal does not specify where these beliefs originated; it simply points to a large number of possible background factors that may influence individuals' beliefs for sharing knowledge in public COPs.

Thus, the Ecuadorian tax administration, through its experts, has identified mainly attitudinal beliefs, social norms and perceived behavioral control as appropriate direct measures of knowledge sharing in COPs. This will allow the authorities and managers of public institutions in our country who want to promote the implementation of COPs to execute different actions and strategies that take into account these beliefs.

\section{ACKNOWLEDGEMENT}

Translated \& edited by American Publishing Services (https://americanpublishingservices.com/).

\section{ENDNOTE}

1. According to the Organic Statute of Organizational Management by Processes of the Internal Revenue Service in force (EC Internal Revenue Service 2016), the Department of Quality Management and Institutional Change is responsible for the institutional knowledge base and the tools and projects for the management of institutional change, products related to knowledge sharing initiatives, such as communities of practice (Wenger 2001).

\section{REFERENCES}

Abela, J. (2016). Las técnicas de análisis de contenido: Una revisión actualizada. Marcelo Astorga. Retrieved May 2, 2019, from https://bit.ly/2D4dk0e

Ajzen, I. (1991). The Theory of Planned Behavior. Organizational Behavior and Human Decision Processes, 50(2), 179-211. https://doi.org/10.1016/0749-5978(91)90020-T

Ajzen, I. (2002). Constructing a TpB Questionnaire: Conceptual and Methodological Considerations. University of Massachussets Amherst. Retrieved January 20, 2018, from https://bit. ly/2PWsHOg 
Ajzen, I. (2011). Behavioral Interventions Based on the Theory of Planned Behavior. University of Massachussets Amherst. Retrieved September 15, 2015, from https://bit.ly/2rX5dAL

Alborníes, Á.L. (2010). La disciplina de la innovación: Rutinas creativas. Madrid: Díaz de Santos.

Ashworth, R.E., McDermott, A.M., \& Currie, G. (2018). Theorizing from Qualitative Research in Public Administration: Plurality through a Combination of Rigor and Richness. Journal of Public Administration Research and Theory, 29(2), 1-16. https://doi.org/10.1093/jopart/muy057

Berger, P., \& Luckmann, T. (1967). Aspects Sociologiques Du Pluralisme. Archives de Sociologie des Religions, 12(23), 117-127. Retrieved from www.jstor.org/stable/30117775

Blanco-Peck, R. (2006). Los enfoques metodológicos y la administración pública moderna. Cinta de Moebio, 27(8), 256-265. Retrieved from https://bit.ly/2D9e8Ru

Bock, G-W., Zmud, R.W., Kim, Y-G., \& Lee, J-N. (2005). Behavioral Intention Formation in Knowledge Sharing. MIS Quarterly, 29(1), 87-111. https://doi.org/10.2307/25148669

Brower, R.S., Abolafia, M.Y., \& Carr, J.B. (2000). On Improving Qualitative Methods in Public Administration Research. Administration \& Society, 32(42), 363-397. https://doi.org/10.1177/00953990022019470

Cassell, C., \& Symon, G. (2006). Taking Qualitative Methods in Organization and Management Research Seriously. Qualitative Research in Organizations and Management: An International Journal, 1(1), 4-12. https://doi.org/10.1108/17465640610666606

Cassell, C., \& Symon, G. (2015). Qualitative Research in Organizations and Management: Ten Years on. Qualitative Research in Organizations and Management: An International Journal, 10(4), 1-11. https://doi.org/10.1108/QROM-10-2015-1329

Chau, P.Y.K., \& Hu, J-H.P. (2001). Information Technology Acceptance by Individual Professionals: A Model Comparison Approach. Decision Sciences, 32(4), 699-719. https://doi.org/10.1111/j.15405915.2001.tb00978.x

Coller, X. (2000). Cuadernos metodológicos: Estudios de casos. Madrid: CIS.

Dodge, J., Ospina, S.M., \& Foldy, E.G. (2005). Integrating Rigor and Relevance in Public Administration Scholarship: The Contribution of Narrative Enquiry. Public Administration Review, 65(3), 286-300. https://doi.org/10.1111/j.1540-6210.2005.0 0454.x

EC Servicio de Rentas Internas. (2016). Plan estratégico organizacional 2016-2019. Quito: SRI. Retrieved from http://bit.ly/33fveaV

Galivene, G., \& Kaufman, E. (2006). Training and Articulating Public Agencies in Argentina. In E. Coakes \& S. Clarke (Eds.), Encyclopedia of Communities of Practice in Information and Knowledge Management (pp. 537-543). Hershey, Idea Group Reference.

Haverland, M., \& Yanow, D. (2012). A Hitchhiker's Guide to the Public Administration Research Universe: Surviving Conversations on Methodologies and Methods. Public Ad-ministration Review, 72(3), 401-408. https://doi.org/10.1111/j.1540-6210.2011.02524.x

Jeon, S-H., Kim, Y.G., \& Koh, J. (2011). Individual, Social, and Organizational Contexts for Active Knowledge Sharing in Communities of Practice. Expert Systems With Applications, 38(10), 12423-12431. https://doi.org/10.1016/j.eswa.2011.04.023

Kirkman, B.L., Cordery, J.L., Mathieu, J., Rosen, B., \& Kukenberger, M. (2013). Global Organizational Communities of Practice: The Effects of Nationality Diversity, Psychological Safety, and Media Richness on Community Performance. Human Relations, 66(3), 333-362. https://doi.org/10.1177/0018726712464076

López Herrera, F., \& Harms, H.S. (2009). La investigación cualitativa en administración. Cinta de Moebio, 35, 128-145. https://doi.org/10.4067/s0717-554x2009000200004

Martínez Marín, J. (2008). Guía para la correcta implantación de comunidades de práctica en entornos de administración pública: Una experiencia de éxito. Red Peruana de Gestores de la Educación. Retrieved August 18, 2012, from https://bit.ly/37ol9Ml

Molina A., Francisco, J., Gamero M.D.L., Moliner, J.P., Ortega, E.M.P., \& Guilló, J.J.T. (2012). Métodos híbridos de investigación y dirección de empresas: Ventajas e implicaciones. Cuadernos de Economía y Dirección de la Empresa, 15(2), 55-62. https://doi.org/10.1016/j.cede.2012.01.001 
Morse, J.M. (1991). Approaches to Qualitative-Quantitative Methodological Triangulation. Nursing Research, 40(2), 120-123. Retrieved from https://bit.ly/2s1OBay

Narváez, G. (2014). Análisis cualitativo, unidades de análisis: presentación de curso. Barcelona: Universidad de Barcelona.

Ospina, S.M., Esteve, M., \& Lee, S. (2017). Assessing Qualitative Studies in Public Administration Research. Public Administration Review, 78(4), 593-605. https://doi. org/10.1111/puar.12837

Ragin, C.C., Nagel, J., \& White, P. (2004). Workshop on Scientific Foundations of Qualitative Research. Arlington: National Science Foundation. Retrieved from https://bit.ly/37rh7CO

Tashakkori, A., \& Creswell, J.W. (2007). The New Era of Mixed Methods. Journal of Mixed Methods Research, 1(1), 3-7. https://doi.org/10.1177/2345678906293042

Wenger, E. (2001). Comunidades de práctica: Aprendizaje, significado e identidad. Buenos Aires: Paidós Ibérica. 